\title{
VASCULAR PARKINSONISM
}

\section{Analysis of seven cases}

\author{
Elton Gomes da Silva', Maura Aparecida Viana², \\ Elizabeth Maria Aparecida Barasnevicius Quagliato ${ }^{3}$
}

\begin{abstract}
Introluction: Ne u roimaging studies of elderly individuals reveal alterations in the white matter that are incompatible with the patient's parkinsonism, mistakenly classified as vascular parkinsonism (VP). Method: This study was conducted on a population composed of 20 patients with Parkinson's disease (PD) whose neuroimaging exams revealed vascular alterations in the white matter and seven patients with VP in order to compare diagnostic criteria. Results: Age at disease onset of patients with PD was $55 \pm 12$ years and patients with VP it was $62 \pm 13$ years. Twelve patients with PD and five patients with VP presented arterial hypertension; three patients with VP and two patients with PD presented gait impairment; all patients with VP presented rigidity and bradykinesia, six of them presented resting tremor; 19 patients with PD presented tremor and 19 of them presented rigidity, while 17 presented bradykinesia. When the symptoms and evolution of both diseases were compared, the vascular alterations in the white matter were considered unspecific. Conclusion: Since clinical symptoms are unspecific, a differential diagnosis requires neuroimaging, good response to levodopa and clinical evolution.
\end{abstract}

KEY WORDS: vascular parkinsonism, Parkinson's disease, diagnosis, neuroimaging.

\section{Parkinsonismo vascular: análise de sete casos}

RESUMO - Introdução: Estudos de neuroimagem em idosos mostram alterações na substância branca que são incompatíveis com o parkinsonismo do paciente, erroneamente classificado como parkinsonismo vascular (PV). Método: Este estudo foi conduzido a partir de uma população de 20 pacientes com doença de Parkinson (DP) cujos exames de neuroimagem revelaram alterações vasculares na substância branca e sete pacientes com PV para comparar os critérios diagnósticos. Resultados: A idade de início da doença dos pacientes com DP foi $55 \pm 12$ anos e pacientes com PV foi $62 \pm 13$ anos. Doze pacientes com DP e cinco pacientes com PV apresentaram hipertensão arterial; três pacientes com PV e dois pacientes com DP apresentaram alteração da marcha; todos os pacientes com PV apresentaram rigidez e bradicinesia, seis deles apresentaram tremor de repouso; 19 pacientes com DP apresentaram tremor e 19 deles apresentaram rigidez, enquanto 17 apresentaram bradicinesia. Quando os sintomas e a evolução de ambas as doenças foram comparadas, as alterações vasculares na substância branca foram consideradas inespecíficas. Con clusão: Como os sintomas clínicos são inespecíficos, um diagnóstico diferencial requer neuroimagem, boa resposta a levodopa e evolução clínica da doença.

PALAVRAS-CHAVE: parkinsonismo vascular, doença de Parkinson, diagnóstico, neuroimagem.

Vascular parkinsonism (VP), first described in 1929 by Critchley ${ }^{1}$, is still viewed as a nosological entity. VP related lesions are considered multiple micro infarcts in the subcortical white matter or in the substantia nigra but their pathophysiology is hetero g eneous and it is not always possible to correlate ischemic lesions with clinical symptoms ${ }^{2-5}$. On the basis of the diagnostic criteria for VP, $4 \%$ to $12 \%$ of patients with Parkinson's syndrome are thought to have a vascular etiology that occurs more frequently in the more aged population ${ }^{1,4,6-10}$.

Despite the criteria utilized, clinical data very often do not help in the diagnosis of VP as shown by pathological studies in which patients with VP were not diagnosed antemort e $\mathrm{m}^{11,12}$. Computerized tomography (CT) and magnetic resonance imaging (MRI) of

Department of Neurology, School of Medicine, State University of Campinas, Campinas SP, Brazil (FCM/UNICAMP): ${ }^{1}$ Medical Student; ${ }^{2} \mathrm{MD} ;{ }^{3}$ Adjunct Professor, responsible for the Movement Disorders Unit, Clinics Hospital, UNICAMP.

Received 11 October 2005, received in final form 1 March 2006. Accepted 4 May 2006.

Dr. Elton Gomes da Silva - Departamento de Neurologia, FCMIUNICAMP - Caixa Postal 6111 - 13083-970 Campinas SP - Brasil. E-mail: elgosi@yahoo.com.br 
the elderly reveal alterations in the white matter that are often correlated with parkinsonian symptoms ${ }^{12,13}$. Lesions with ischemic characteristics revealed by the neuroimaging exams should not be the main criteria for diffe rential diagnosis of VP and other forms of parkinsonism since $20 \%$ to $30 \%$ of the Parkinson's disease (PD) exams present ischemic alterations ${ }^{2,3}$.

These exams are useful for determining localized vascular lesions and excluding other causes of second a ry parkinsonism such as normal pressure hydro cephaly and lesions with mass effect.

\section{METHOD}

This study was designed to describe the clinical symptoms and the MRI of seven patients with VP and compare them with 20 patients with PD whose neuroimaging exams revealed vascular lesions with ischemic characteristics. This study also evaluated the criteria for a differential diagnosis of these two forms of parkinsonism and verified the existence of a clinical-radiological distincti on between these two etiologies.

This comparison was proposed so that the clinical diffe rences between the two forms of parkinsonism could be evaluated because the neuroimaging results of all the patients revealed vascular alterations that did not allow for a definite diagnosis of the cause.

The inclusion criteria used for the diagnosis of PD were: presence of at least two of the following signs - tremor at rest, akinesia / bradykinesia, rigidity and altered postural reflexes; unilateral onset of the symptoms and asymmetrical development of the disease; a good response to L-dopa. The criteria for exclusion were: pyramidal symptoms, cerebellar symptoms and autonomic failure at disease onset; a history of drug and substance abuse, encephalitis and/or a relationship between cerebral vascular accident (CVA) and onset of Parkinson's syndrome 8,12,14,15.

The inclusion criteri a for VP were: acute or sub-acute evolution; presence of rigidity or bradykinesia, focal signs or symptoms consistent with stroke such as pyramidal with symmetric compromise, vascular risk factors - systemic art erial hypertension (SAH), prior ischemic CVA and atherosclerotic disease; association with pseudobulbar paralysis and spontaneous improvement of the symptoms; unsatisfactory or absence of response to L-dopa; MRI that revealed at least two basal ganglia infarcts or diffused disease of the white matter. The criteria for exclusion were: antecedents of cranioencephalic traumatism, defined encephalitis, treatment with neuroleptics at onset of symptoms, CT or MRI demonstrating presence of cerebral tumor or communicating hydrocephaly $1,4,6,7,12$.

The criteria established by the Diagnostic and Statistical Manual of Mental Disorders (DSM-IV) were used to classify dementia and depression ${ }^{16}$.

Follow up of all the patients was perf o rmed at the Movement Disorders Outpatient Unit of the Department of Neurology, Clinics Hospital, State University of Campinas (HC/UNICAMP) and the patients also underwent MRI exams. The PD cases whose MRI exams revealed vascular lesions and all the VP cases were selected from a list of patients treated between 1999 and 2001 at the Outpatient Unit, and this study was initially approved for the Committee of Ethics in Research of School of Medicine of UNICAMP (CEP/ FCM/UNICAMP).

The magnetic resonance equipment ELSCINT with potency of two Tesla was used for the neuroimaging exams.

The factors analyzed in both groups were: age at disease onset, time of evolution, sex, clinical symptoms and localization, related comorbidities and MRI alterations.

The chi-square test was applied for analyzing the variables. The significance level established was $p<0.05$.

\section{RESULTS}

Twenty patients with PD were compared with seven patients with VP. Table 1 presents the mean age at disease onset, duration of disease, sex and clinical symptoms.

Five patients with VP presented acute onset of symptoms post CVA and two patients presented a prog ressive condition that stabilized after six months. Six of the patients with VP presented symmetry of symptoms at disease onset.

In the group of patients with VP, one patient presented partial response to L-dopa, which was lost three months after disease onset.

Both groups were evaluated regarding vascular risk factors and associated comorbidities such as: CVA antecedents, dementia, SAH, and depression. These values are presented in Table 2.

Table 1. Age at onset, duration of disease, sex and clinical symp toms of $P D$ and $V P$.

\begin{tabular}{lcc}
\hline Diagnosis & $\mathrm{PD}$ & $\mathrm{VP}$ \\
\hline Age at onset (years) & $55.5 \pm 12.2$ & $61.8 \pm 13.7$ \\
Duration of disease (years) & $11.2 \pm 8.6$ & $8.5 \pm 3.9$ \\
Sex (M/F) & $11 / 9$ & $4 / 3$ \\
Tremor & $19(95 \%)$ & $6(85.7 \%)$ \\
Rigidity & $19(95 \%)$ & $7(100 \%)$ \\
Bradykinesia & $17(85 \%)$ & $5(71.4 \%)$ \\
Posture instability & $7(35 \%)$ & $2(28.6 \%)$ \\
\hline
\end{tabular}

*p<0.05; PD, Parkinson's disease; VP, vascular parkinsonism; M, male; F, female.

Table 2. PD and VP associated comorbidities.

\begin{tabular}{lcc}
\hline Comorbidity & PD & VP \\
\hline Cerebral vascular accident & $8(40 \%)$ & $7(100 \%)^{*}$ \\
Dementia & $1(5 \%)$ & $3(43 \%)^{*}$ \\
Systemic arterial hypertension & $12(60 \%)$ & $5(71 \%)$ \\
Depression & $1(5 \%)$ & $3(43 \%)^{*}$ \\
\hline
\end{tabular}

${ }^{*} \mathrm{p}<0.05 ; \mathrm{PD}$, Parkinson's disease; VP, vascular parkinsonism. 
Table 3. Number of patients with PD or VP demonstrating vas cular alterations in MRI.

\begin{tabular}{lcl}
\hline Vascular lesions & PD & VP \\
\hline PVWM & 9 & 0 \\
SCWM & 5 & 5 \\
BN & 3 & 0 \\
PVWM + SCWM & 1 & 0 \\
PVWM + BN & 0 & 2 \\
SCWM + BN & 2 & 0 \\
\hline
\end{tabular}

$\mathrm{MRI}$, magnetic resonance imaging; PD, Parkinson's disease; $\mathrm{VP}$, vascular parkinsonism; PVWM, periventricular white matter; SCWM, subcortical white matter; BN, basal nucleus.

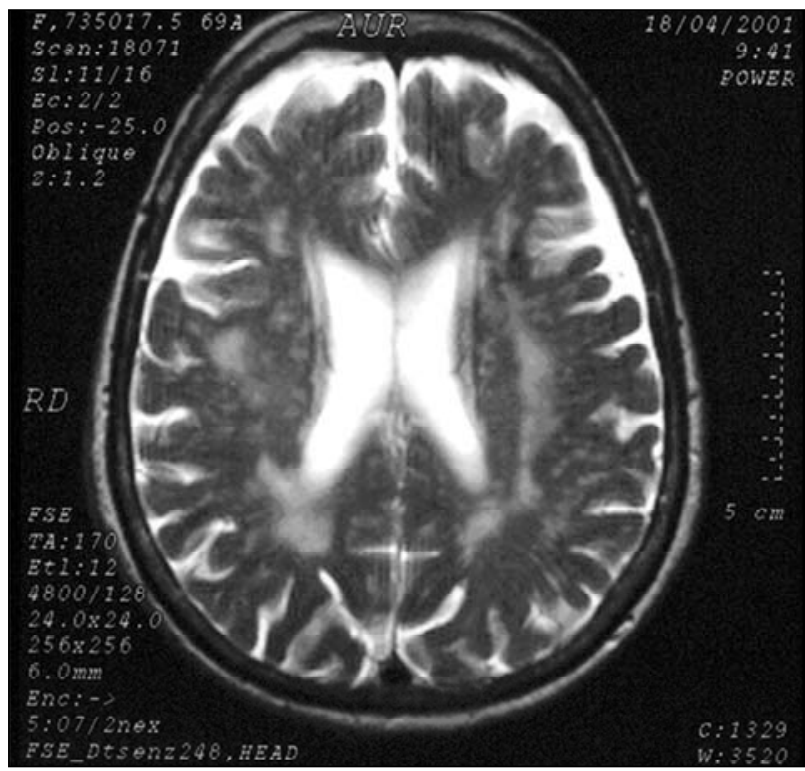

Fig 1. Magnetic resonance imaging of a 69 year-old patient with Parkinson's disease revealed multiple ischemic lesions in the subcortical white matter.
The MRI exams revealed lesions compatible with vasculopathy in the periventricular white matter (PVWM), subcortical white matter (SCWM) and basal nuclei (BN) as shown in Table 3.

The MR images of the patients are shown in Figs 1 and 2.

\section{DISCUSSION}

Since VP is very often sub-diagnosed or mimics PD or some other degenerative disease such as progressive supranuclear paralysis or corticobasal degeneration, it is rarely cited as the cause of $\mathrm{PD}^{4,11,17}$. Our study population, which consisted of PD and VP groups, did not demonstrate a statistically significant difference between disease onset and sex or clinical symptoms, contradicting reports that symptom onset occurred at a more advanced age and that there was a discreet male predominance in the VP gro $u p^{1,2,8,10}$. Resting tremor was less frequently encountered in other studies, which was probably due to the fact that posture tremor is common in patients with VP, but it was a factor observed in this study ${ }^{11,12}$. Therefore, it should not be used as a criterion of exclusion for VP since it may be observed in some patients ${ }^{12}$.

Other symptoms were found in similar proportions in both groups. A typical history of acute and symmetrical symptoms was observed in the patients with VP, although the acute condition occurred in less than half of the patients in the other studies ${ }^{2,3,12}$.

The presence of comorbidities (CVA, dementia, $\mathrm{SAH}$, depression) was significantly greater in patients with VP, which was similar to other studies ${ }^{2,3,10-12}$.
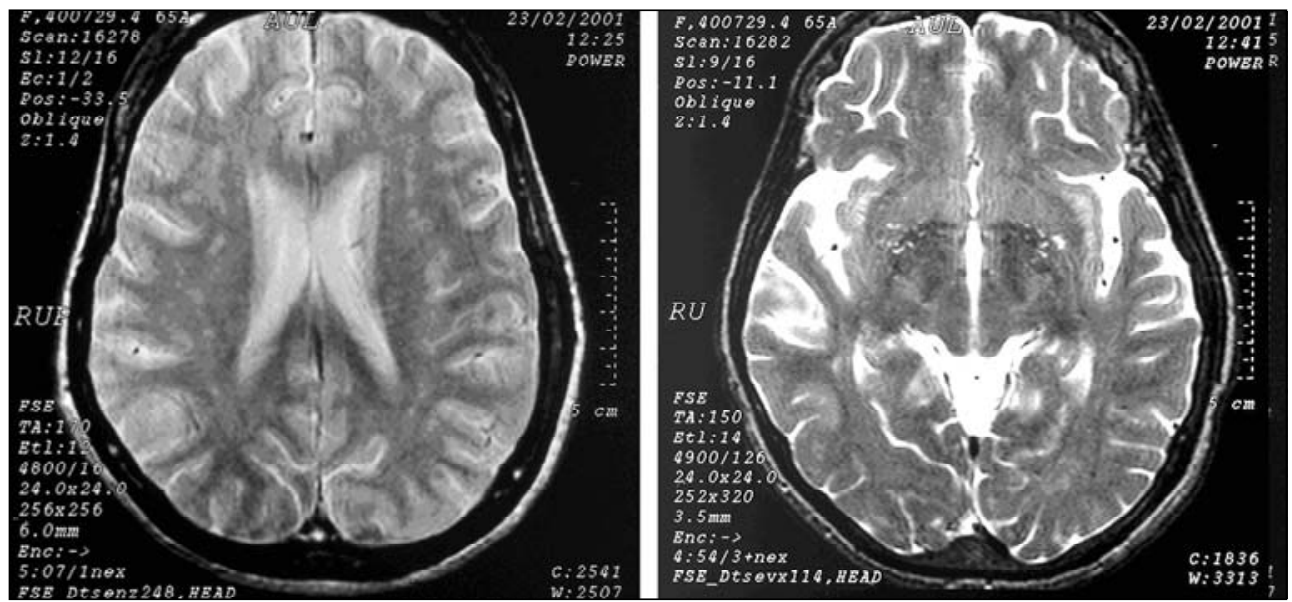

Fig 2. Sixty five year-old patient with a diagnosis of vascular parkinsonism. The magnetic resonance image revealed perivascular space enlargement in the basal nuclei and cerebral peduncles as well as ischemic lesions in the white periventricular and subcortical matter. 
The reare re ports in the literature of a clinical imp rovement in some patients with VP when subjected to dopaminergic therapy. This was observed in one patient in our study, but loss of response occurred three months after treatment began ${ }^{4,12,18}$. The lesions revealed in the exams of patients with PD did not alter disease evolution or the severity of the clinical symptoms as observed in another study ${ }^{19}$.

Although the majority of the patients with PD presented vascular lesions in the periventricular white matter, lesions were also found in the basal nuclei and subcortical white matter, which made it a complementaryexam in the etiology of the condition useful for the confirmation and localization of vascular lesions and exclusion of other causes for symptomatology, but didn't help in obtaining a differential diagnosis for PD and VP2,4,12,20.

Differential diagnosis was based on the clinical symptoms that were present, L-dopa response and clinical evolution of patients with altered exam results, the latter was used for triage of the patients ${ }^{2,3,12}$.

It must be remembered that VP is an important cause of parkinsonism although it is underdiagnosed. It has typical characteristics of bilateral and symmetrical onset, rigidity or bradykinesia, absence of response to L-dopa and altered neuroimaging exams compatible with vascular lesions.

Underdiagnosis is common, since the right diagnosis for VP is pathological, but a presumptive diagnsis can be made based on clinical data assessment and neuroimaging exams since together they enhance diagnostic clarity despite symptom heterogeneity.

Since vascular alterations in the white matter may be found in the same locality in the brain imaging exams in PD and VP with different symptoms, they cannot be used as the only parameter for VP diagnosis, making it necessary to have an assessment of clinical evolution as well as altered exams and the presence of vascular risk factors. Further studies are being conducted to increase the sensitivity of the criteria being used for the diagnosis of VP and also to enhance knowledge re $\mathrm{g}$ a rding the pathophysiology of this disease.

\section{REFERENCES}

1. Critchley M. Arteriosclerotic parkinsonism. Brain 1929;52:23-83.

2. Winikates J, Jankovic J. Clinical correlates of vascular parkinsonism. Arch Neurol 1999;56:98-102.

3. Demirkiran M, Bozdemir H, Sarica Y. Vascular parkinsonism: a distinct, heterogeneous clinical entity. Acta Neurol Scand 2001;104:63-67.

4. Thanvi B, Lo N, Robinson T. Vascular parkinsonism: an important cause of parkinsonism in older people. Age Ageing 2005;34:114-119.

5. Zijlmans JCM, Thijssen HOM, Vogels OJM, et al. MRI in patients with suspected vascular parkinsonism. Neurology 1995;45:2183-2188.

6. Bennet DA, Wilson RS, Gilley DW, Fox JH. Clinical diagnosis of Binswanger disease. J Neurol Neurosurg Psychiatry 1990;53:961-965.

7. Hurtig HI. Vascular parkinsonism. In: Stern MB, Koller WC (eds). Parkinsonian syndromes. New York: Marcel Dekker, 1993:81-83.

8. Baldereschi M, Di Carlo A, Rocca WA, et al. Parkinson's disease and parkinsonism in a longitudinal study: two-fold higher incidence in men. Neurology 2000;55:1358-1363.

9. Foltynie T, Barker R, Brayne C. Vascular parkinsonism: a review of the $p$ recision and frequency of diagnosis. Neuroepidemiology 2002;21: $1-7$

10. Benito-Leon J, Bernejo-Pareja F, Moralez-Gonzalez JM, et al. Incidence of Parkinson's disease and parkinsonism in three elderly populations of central Spain. Neurology 2004;62:734-741.

11. Bower JH, Dickson DW, Taylor L, Maraganore DM, Rocca WA. Clinical correlates of the pathology underlyng parkinsonism: a population perpective. Mov Disord 2002;17:910-916.

12. Zijlmans JCM, Daniel Se, Hughes AJ, Révész T, Lees AJ. Clinicopathological investigation of vascular parkinsonism, including clinical criteria for diagnosis. Mov Disord 2004;19:630-640.

13. Fazekas F, Niederkorn K, Schmidt R, et al. White matter signal abnormalities in normal individuals: correlation with carotid ultrasound, c e rebral blood flow measurements, and cerebrovascular disease risk factors. Stroke 1988;19:1285-1288.

14. Larsen JP, Dupont E, TandbergE. Clinical diagnosis of Parkinson's disease: proposal of diagnostic subgroups classified at different levels of confidence. Acta Neurol Scand 1994;89:242-251.

15. Elbaz A, Bower JH, Maraganore DM, et al. Risk tables for parkinsonism and Parkinson's disease. J Clin Epidemiol 2002;55:25-31.

16. American Psychiatric Association. Diagnostic and statistical manual of mental disorders. fourth edition. Washington, DC: American Psychiatric Association, 1994.

17. Sibon I, Fenelon G, Quinn NP, Tison F. Vascular parkinsonism. J Neurol 2004;251:513-524.

18. Zijlmans JCM, Katzenschlager R, Daniel SE, Lees AJL. The L-dopa response in vascular parkinsonism. J Neurol Neuro su rgPsychiatry 2004; 75:545-547.

19. Piccini P, Pavese N, Canapichi R, et al. White matter hiperintensities in Parkinson's disease. Arch Neurol 1995;52:191-194.

20. Murrow RW, Schweiger GD, Kepes JJ, Koller WC. Parkinsonism due to basal lacunar state: a clinicopathological correlation. Neurology 1990; 40:897-900 